\title{
Proton Conducting Glasses from Zeolite Materials
}

\section{Manabu KOIDE, ${ }^{\text {a,* }}$ Masanao KATO, ${ }^{\text {a }}$ Tomohiro SATO, $^{\mathrm{b}}$ and Shio KUDO ${ }^{c}$}

\author{
a Department of Materials Engineering, Nagaoka National College of Technology, \\ 888 Nishikatagai, Nagaoka, Niigata 940-8532, Japan \\ b Sinter Land Inc., 123 Ameike, Nagaoka, Niigata 940-2101, Japan \\ c Department of Material Science, Graduate School of Engineering, Iwate University, Morioka 020-8551, Japan \\ * Corresponding author: koide@nagaoka-ct.ac.jp
}

\begin{abstract}
Proton conducting glasses were prepared from proton type zeolite materials by the spark plasma sintering technique in vacuum. TOF-SIMS analysis showed that the glass structure contains protons. The electrical conductivity was affected by proton content and probably by the pore structure of the starting zeolite material.

(C) The Electrochemical Society of Japan, All rights reserved.
\end{abstract}

Keywords : Zeolite, Proton Conduction, Glass, Spark Plasma Sintering (SPS)

\section{Introduction}

Zeolite is an alumino silicate crystal material having a micro porous structure. Due to this micro porous structure, zeolite materials are used as molecular sieves and as solid catalyst for oil production.

Recently, there is high expectation for the use of zeolite materials in electrochemistry and optics, ${ }^{1-3}$ specifically in the fabrication of fuel cells.

Proton conductors are essential components in hydrogen fuel cells. Several works have been carried about their physical properties and working temperatures. ${ }^{4-6}$

Phosphate glasses are known as good proton conductors but they have low resistance to water and humidity. ${ }^{7-9}$ In humid atmosphere, conductors made from phosphate glasses become mechanically weak, a hurdle for the fabrication of conductors with large size.

Silicate based glasses have good resistance to humidity. However, those prepared by the conventional melting method are generally poor proton conductors. This is because hydrogen cannot be introduced with large enough content in silicate based glasses by the conventional melting method.

In the present study, we report on the preparation of silicate based glasses with high proton content and having a structure with high number of free channels (bypass for protons) from zeolite material using the spark plasma sintering technique. ${ }^{10}$

\section{Experimental Procedure}

The first basic zeolite material used in this study is sodium type mordenite, 642NAA $\left(\mathrm{SiO}_{2} / \mathrm{Al}_{2} \mathrm{O}_{3}\right.$ ratio $\left.18, \mathrm{Na}_{2} \mathrm{O} 5.0 \mathrm{wt} \%\right)$, from Tosoh Corporation. This material underwent an ion exchange treatment to exchange sodium cations with protons via ammonium ion exchange to produce proton type mordenite, 640HOA $\left(\mathrm{SiO}_{2} /\right.$ $\mathrm{Al}_{2} \mathrm{O}_{3}$ ratio $18, \mathrm{Na}_{2} \mathrm{O} 0.05 \mathrm{wt} \%$ ).

Faujasite is as another basic zeolite material used in this study. In a similar way to mordenite, faujastite material underwent an ion exchange treatment to produce proton type faujasite of 331HSA $\left(\mathrm{SiO}_{2} / \mathrm{Al}_{2} \mathrm{O}_{3}\right.$ ratio $\left.14, \mathrm{Na}_{2} \mathrm{O} 0.2 \mathrm{wt} \%\right)$ and also proton type faujasite of $360 \mathrm{HUA}\left(\mathrm{SiO}_{2} / \mathrm{Al}_{2} \mathrm{O}_{3}\right.$ ratio $\left.14, \mathrm{Na}_{2} \mathrm{O} 0.05 \mathrm{wt} \%\right)$.

After ion exchange, samples were sintered using the Spark Plasma Sintering machine MK320 of Sumitomo Coal Mining Corporation. ${ }^{10}$
For sample sintering, zeolite samples of $5 \mathrm{~g}$ were filled in a graphite mold with $20 \mathrm{~mm}$ in diameter and pressed at $40 \mathrm{MPa}$. They were then heated to $1473-1573 \mathrm{~K}$ at a heating rate of $50 \mathrm{~K} / \mathrm{min}$. After that, they were cooled down to room temperature for characterization. The crystal structure of the sintered sample was analyzed using X-ray diffraction. The presence of protons and their structure were analyzed by TOF-SIMS (Time of Flight Secondary Ion Mass Spectrometry). The electrical conductivity of the sintered samples was measured at between $400-650^{\circ} \mathrm{C}$ using AC impedance with two-probe in air.

\section{Result and Discussion}

Samples prepared at $1475 \mathrm{~K}$ from sodium type mordenite of 642NAA and proton type mordenite of 640HOA were transparent. Their X-ray diffraction patterns are shown in Fig. 1.

Sodium type mordenite of 642NAA sample has a broad hallow pattern characteristic of a pure amorphous structure. However, Proton type mordenite of $640 \mathrm{HOA}$ sample has in addition to a broad hallow pattern, small peaks related to traces of a crystal structure. The crystal was identified to mullite. Further increase in sintering temperature did not demolish mullite.

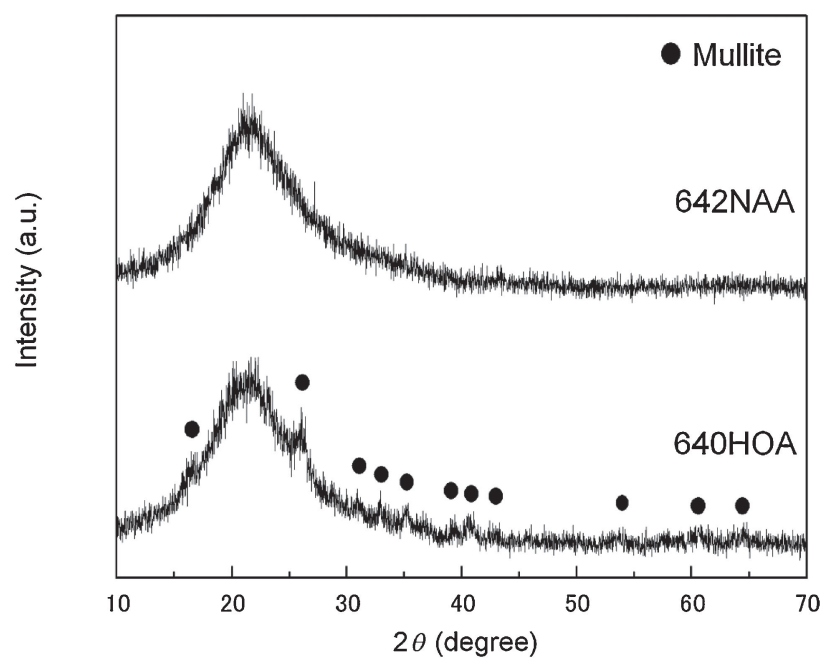

Figure 1. X-ray diffraction patterns of samples prepared by sintering of $640 \mathrm{HOA}$ and $642 \mathrm{NAA}$. 


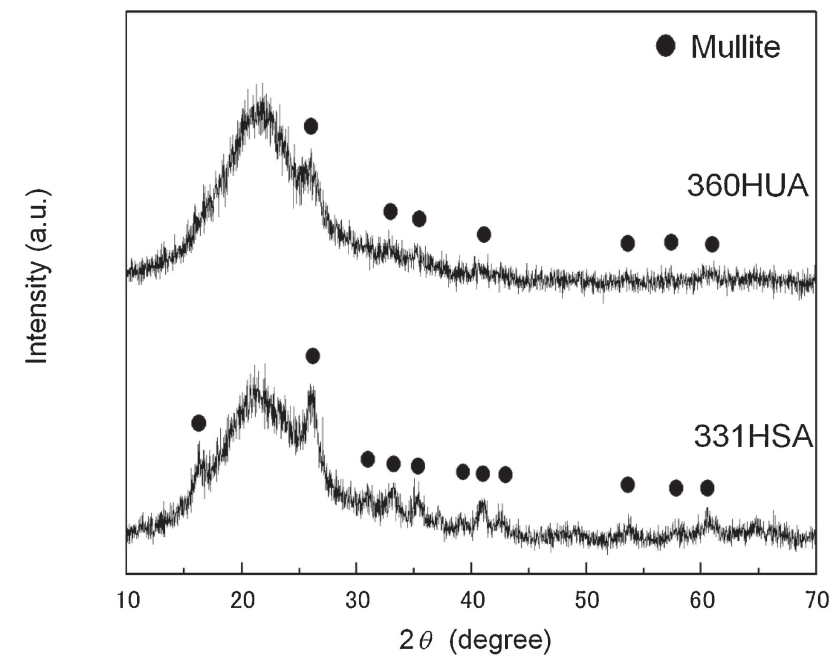

Figure 2. X-ray diffraction patterns of samples prepared by sintering of 331HSA and 360HUA.

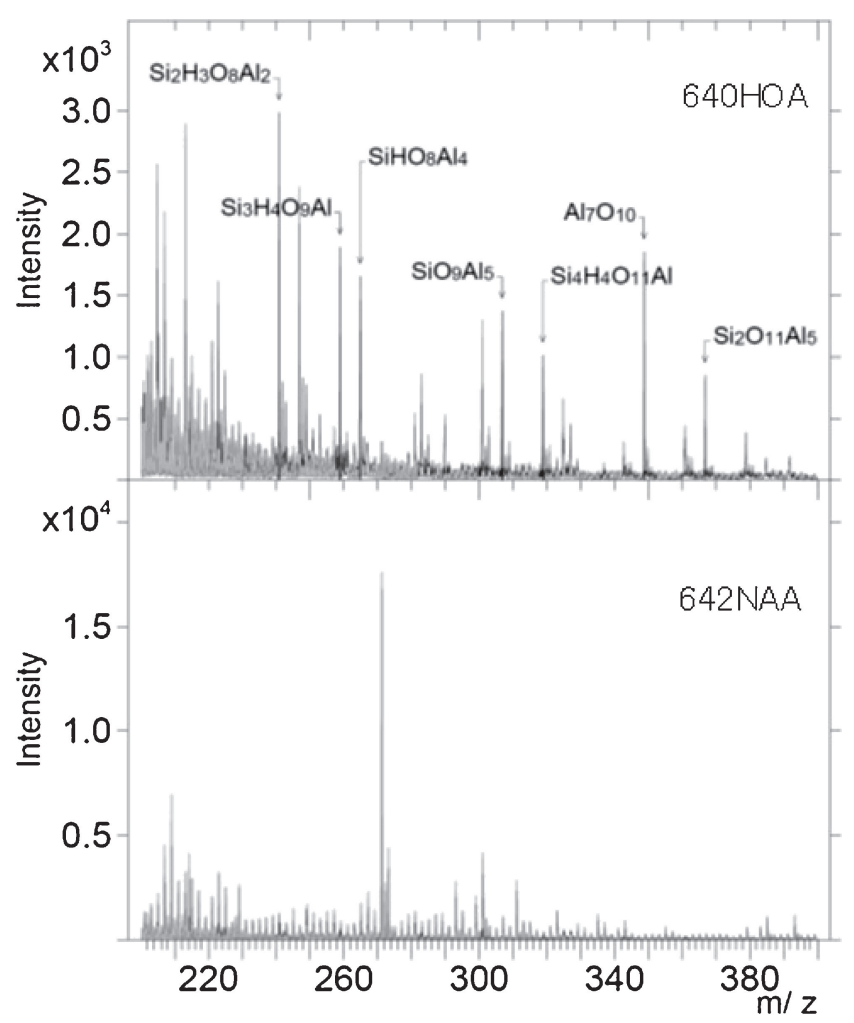

Figure 3. TOF-SIMS spectrum of samples prepared by sintering of $640 \mathrm{HOA}$ and $642 \mathrm{NAA}$.

Samples prepared at $1475 \mathrm{~K}$ from proton type faujasite of $331 \mathrm{HSA}$ and $360 \mathrm{HUA}$ were also transparent. Their X-ray diffraction patterns are shown in Fig. 2. Both samples have a broad hallow pattern with traces of mullite crystal too.

TOF-SIMS analysis for sodium type modernite sample of 642NAA and proton type mordenite sample of 640HOA is shown in Fig. 3. The chemical composition of most identified fragments for proton type mordenite sample of 640HOA contain hydrogen, an indication that the sample contains hydrogen in its structure.

Figure 4 show TOF-SIMS result in the range of 17.98 to $19.06 \mathrm{~m} / \mathrm{z}$ for proton type modernite sample of $640 \mathrm{HOA}$. Peaks observed in this range are attributed to $\mathrm{H}_{2} \mathrm{O}$ and $\mathrm{H}_{3} \mathrm{O}^{+}$. This result indicates that at least a fraction of hydrogen introduced in the proton mordenite sample of $640 \mathrm{HOA}$ does exist in the form of water $\left(\mathrm{H}_{2} \mathrm{O}\right)$ and hydronium ion $\left(\mathrm{H}_{3} \mathrm{O}^{+}\right)$.
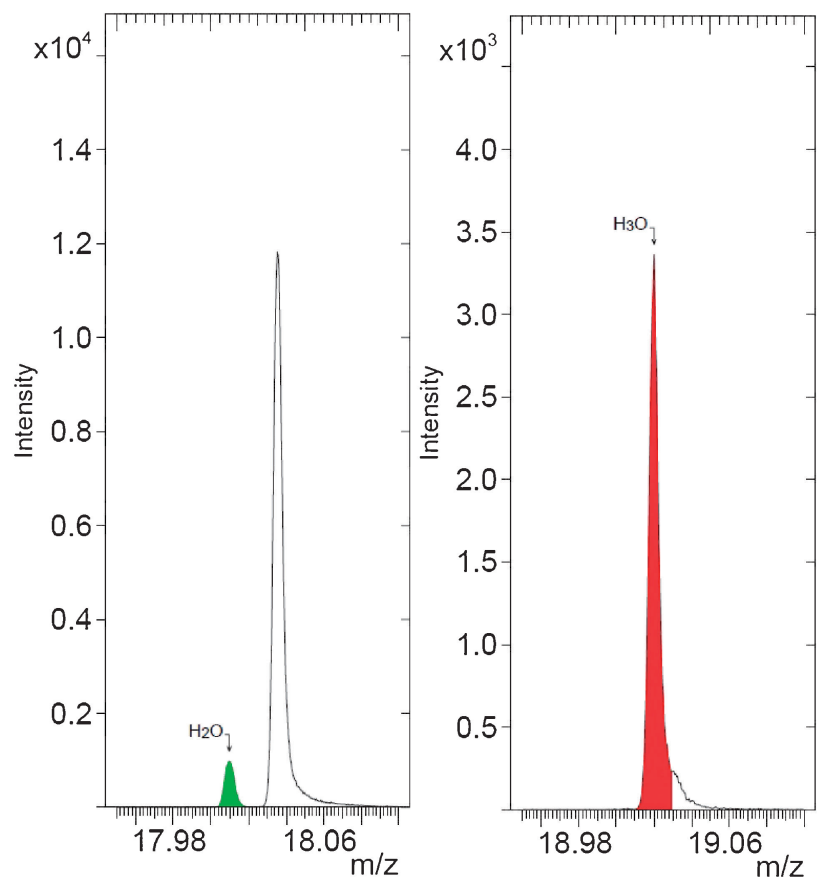

Figure 4. TOF-SIMS of the proton type modernite sample of $640 \mathrm{HOA}$ between 17.98 and $19.06 \mathrm{~m} / \mathrm{z}$.

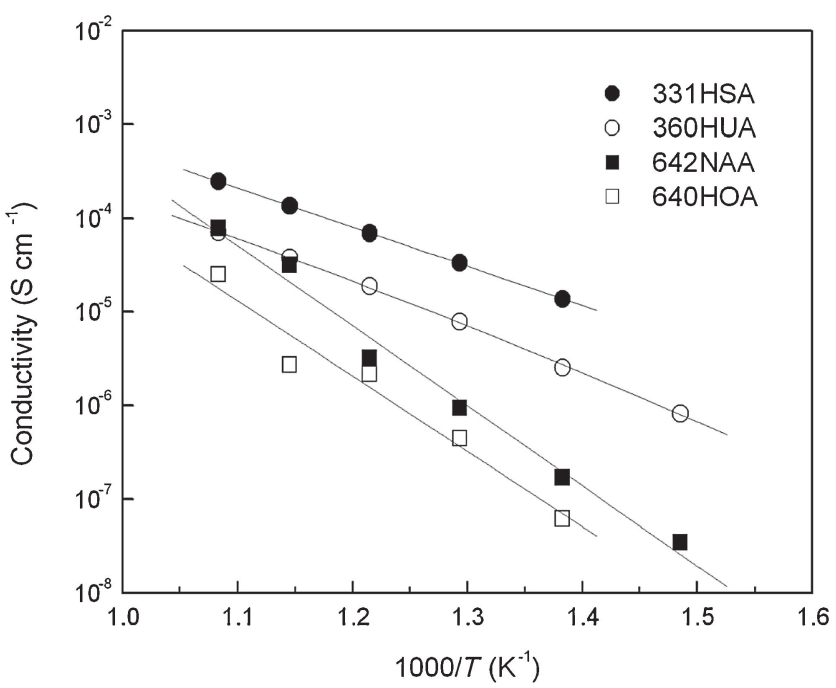

Figure 5. Plots of log conductivity versus reciprocal temperature for samples obtained by the present method.

Figure 5 shows the electrical conductivity dependence on temperature for mordenite and faujasite samples.

Proton type mordenite sample of $640 \mathrm{HOA}$ has an electrical conductivity close to that of sodium type mordenite sample of 642NAA. The possible carriers in this latter are sodium cations. However, in proton type mordenite sample of 640HOA sodium content is much lower so that the remaining sodium cations cannot be the only carriers in this sample otherwise the electrical conductivity should be much smaller $(1 / 100)$ than that in sodium type mordenite. The presence of fragments containing hydrogen as well as hydronium ions $\left(\mathrm{H}_{3} \mathrm{O}^{+}\right)$in proton type mordenite sample of $640 \mathrm{HOA}$ points to the fact that the other possible carriers in this sample are protons. Hence, we can say that the proton type mordenite sample of 640HOA produced in this study has the property of a proton conducting glass.

TOF-SIMS analysis for faujasite samples of 331HSA and 360HUA were not carried out but they are proton conducting 
Table 1. Activation energy of electrical conductivity.

\begin{tabular}{cc}
\hline Zeolite & Activation energy $(\mathrm{kJ} / \mathrm{mol})$ \\
331HSA & 80 \\
360HUA & 93 \\
642NAA & 164 \\
640HOA & 153 \\
\hline
\end{tabular}

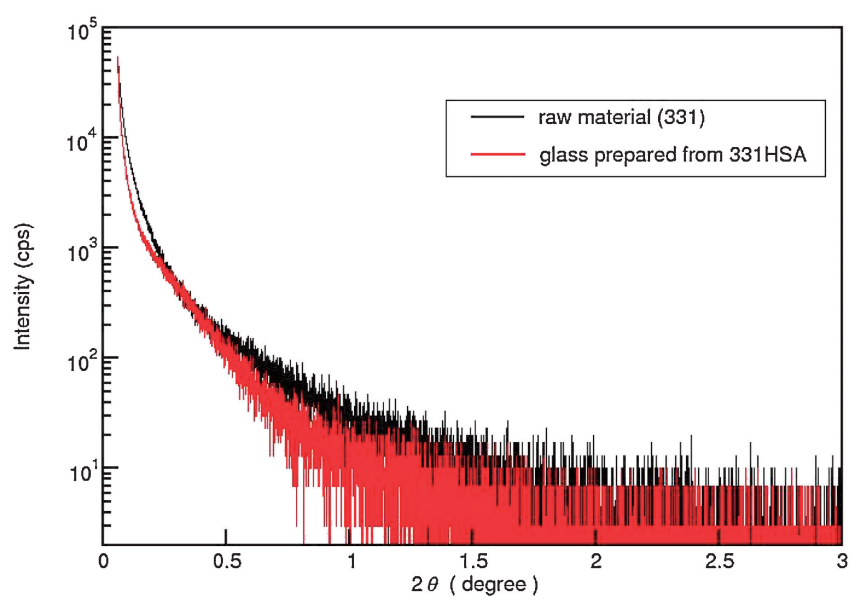

Figure 6. Small angle diffraction of X-ray for proton type faujasite sample of 331HSA before and after sintering.

samples too as will be confirmed later by the measurement of the performance of faujasite sample of 331HSA as a hydrogen concentration cell under partial pressure of hydrogen.

Faujasite samples have higher electrical conductivity than that of mordenite samples. This is attributed to the difference in chemical composition and structure.

In faujasite samples, the relative alumina to silica content $\left(\mathrm{SiO}_{2} /\right.$ $\left.\mathrm{Al}_{2} \mathrm{O}_{3}: 14\right)$ is higher than that in mordenite samples $\left(\mathrm{SiO}_{2} / \mathrm{Al}_{2} \mathrm{O}_{3}: 18\right)$. Higher $\mathrm{Al}_{2} \mathrm{O}_{3}$ content may be favoring the introduction of more protons. This is on one hand and on the other hand, faujasite samples have a structure containing three dimension structure pores. In contrast, mordenite samples have a structure containing one dimension structure pores. The mobility of carriers through three dimension structure pores is easier than that through one dimension structure pores. This difference in pore structure between faujasite and mordenite samples might be another factor at the origin of the higher electrical conductivity in the faujasite samples.

Table 1 shows the activation energy of the electrical conductivity for mordenite and faujasite samples.

The lower activation energy of Faujasite samples highlights the fact that as indicated above pore structures in both type of samples and to less extent the difference in composition are affecting the mobility of protons.

Figure 6 shows small angle diffraction of X-ray for proton type faujasite sample of 331HSA before and after sintering. The broad scattering peak at below 1.0 degree is attributed to pores present in the structure. The strength and form of the peak was modified but was not demolished completely by the sintering. This indicates that pores might be affected in size and number but still present in the structure. The size and content of pores effects on the mobility are under investigation.

Figure 7 shows the performance of proton type faujasite sample of 331HSA as a hydrogen concentration cell under various hydrogen partial pressure.

The size of faujasite sample of 331HSA used in the experiment was $20 \mathrm{~min}$ in diameter and $2.5 \mathrm{~mm}$ in thickness. Pt electrodes were

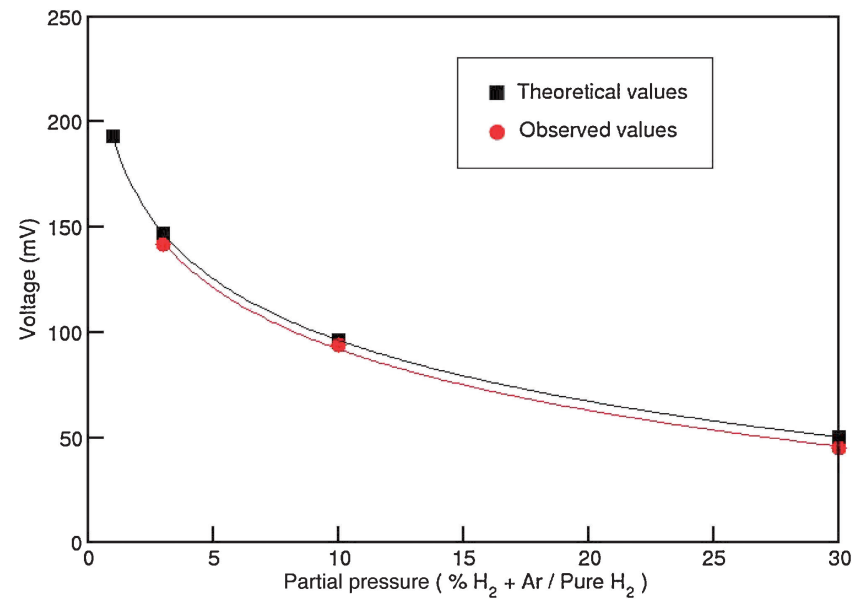

Figure 7. The dependence of the generated power on hydrogen partial pressure in hydrogen concentration cell system.

coated on its surface using Pt paste type TR-7601 of Tanaka Metals Co. Electrodes were fired at $930^{\circ} \mathrm{C}$ for $1 \mathrm{hr}$. The diameter of the electrodes was $10 \mathrm{~mm}$. Each surface of the sample was sealed with a silica tube through which hydrogen was flown on one surface and a mixture of hydrogen and argon was flown on the other one. The measurement was carried in a furnace heated to $700^{\circ} \mathrm{C}$.

The voltage generated was measured using a multi meter connected to the sample electrodes through Pt wires.

As can be understood from measurement, the voltage generated is dependent on hydrogen partial pressure. It does increase with decreasing the partial pressure of hydrogen. The measured values are also found to be in agreement with those theoretically calculated by Nernst equation.

Further studies will be carried in order to clarify the relation between electrical conductivity, carrier type, carrier content and pore structure.

\section{Conclusion}

In summary, proton conducting glasses were developed from proton type zeolite materials using the sintering technique. The electrical conductivity of the glass was affected by proton carrier content and pore structure of zeolite material used.

\section{Acknowledgment}

The author would like to thank Prof. K. Sato from Nagaoka University of Technology and Dr. K. Jabri from SINTER LAND Inc. for providing some properties measurement and data analysis.

\section{References}

1. O. Terasaki, K. Yamazaki, J. M. Thomas, T. Ohsuna, D. Watanabe, J. V. Sanders, and J. C. Barry, Nature, 330, 58 (1987).

2. Y. Nozue, T. Kodaira, and T. Goto, Phys. Rev. Lett., 68, 3789 (1992).

3. N. Herron, Y. Wang, M. M. Eddy, G. D. Stucky, D. E. Cox, K. Moller, and T. Bein, J. Am. Chem. Soc., 111, 530 (1989).

4. T. Norby, Solid State Ionics, 125, 1 (1999).

5. A. I. Baranov, B. V. Merinov, A. V. Tregubchenko, V. P. Khiznichenko, L. A. Shuvalov, and N. M. Schagina, Solid State Ionics, 36, 279 (1989).

6. J. Garbarczyk, Mater. Sci. Forum, 76, 87 (1991).

7. Y. Abe, M. Hayashi, T. Iwamoto, H. Sumi, and L. L. Hench, J. Non-Cryst. Solids, 351, 2138 (2005).

8. H. Hosono, K. Kawamura, H. Kawazoe, N. Matsunami, and Y. Abe, J. Appl. Phys., 81, 1296 (1997).

9. T. Uma and M. Nogami, J. Non-Cryst. Solids, 351, 3325 (2005).

10. M. Koide, S. Takei, T. Sato, and K. Matusita, J. Ceram. Soc. Jpn., 110, 867 (2002). 